\title{
Effect of docetaxel on the regulation of proliferation and apoptosis of human prostate cancer cells
}

\author{
CHONGYI YANG ${ }^{1-3}$, WEIJIE ZHANG ${ }^{2,3}$, JIE WANG $^{2,3}$, PENGPENG CHEN $^{2,3}$ and JIANGJIANG JIN ${ }^{2,3}$ \\ ${ }^{1}$ School of Medicine, Ningbo University, Ningbo, Zhejiang 315211; ${ }^{2}$ Department of Urology, Ninghai First Hospital; \\ ${ }^{3}$ Department of Urology, Ninghai Hospital, Branch of Shanghai Tenth People's Hospital, Ninghai, Zhejiang 315600, P.R. China
}

Received May 10, 2018; Accepted November 28, 2018

DOI: $10.3892 / \mathrm{mmr} .2019 .9998$

\begin{abstract}
Prostate cancer is a common type of malignancy. Given the complexity of prostate cancer and the pressing challenge of chemoresistance, the current study was conducted to investigate the effect of docetaxel (Doc) on androgen receptor (AR)-dependent and AR-independent prostate cancers cells. Subsequent experiments were designed to explore the mechanism underlying the Doc-induced apoptosis. Three different human prostate cancer cell lines, namely PC-3, LNCaP and DU-145, were exposed to various concentrations of Doc. The cytotoxic effects of Doc were evaluated by an MTT assay, while apoptosis and cell cycle distribution were determined by flow cytometric analysis of cells stained with Annexin V-FITC and propidium iodide. Western blot assay was also used to measure the protein levels of B-cell lymphoma 2 (Bcl-2), Bcl-2-associated death promoter (Bad), total protein kinase B (Akt), phospho-Akt and caspase-3/9. Doc induced cytotoxicity in all three cell lines in a dose-dependent manner. The half maximal inhibitory concentration values for the effect of Doc on PC-3, DU-145 and LNCaP cells were 3.72, 4.46 and $1.13 \mathrm{nM}$, respectively. Furthermore, the results indicated a significant difference in Doc sensitivity between AR-dependent and AR-independent prostate cancer cells. Evaluation of key gene expression at protein levels revealed a notable decrease in antiapoptotic Bcl-2 and p-Akt levels, along with a significant increase in pro-apoptotic Bad, caspase-3 and caspase-9 levels. Therefore, Doc may induce cell apoptosis in prostate cancer via various pathways.
\end{abstract}

\section{Introduction}

Prostate cancer is the most frequently diagnosed non-cutaneous cancer in males in western countries (1). The majority of

Correspondence to: Dr Jiangjiang Jin, Department of Urology, Ninghai First Hospital, 142 Taoyuan Zhong Road, Ninghai, Zhejiang 315600, P.R. China

E-mail: injcp91@163.com

Key words: prostate cancer, docetaxel, androgen receptor, B-cell lymphoma 2, caspase prostate cancer cases are diagnosed at a local stage and have a 5-year survival rate of almost $100 \%$ (2). However, prostate cancer remains a major cause of cancer-associated mortality due to its heterogeneous nature, ranging from asymptomatic to a rapidly fatal systemic malignancy. One of the most challenging aspects of prostate cancer is that the androgen receptor-dependent tumors inevitably progress to highly aggressive castration-resistant tumors following initial androgen-ablation therapy.

Only a limited number of effective therapeutic options are available for advanced prostate cancer. Docetaxel (Doc), a semi-synthetically taxane analogue, has displayed promising therapeutic potential in treating advanced-stage prostate cancer. In clinical practice, it is recommended that combination of Doc and prednisone should be used in the treatment of prostate cancer patients to improve overall survival and disease control (3). However, progression is ultimately observed after 6-8 months in patients treated with Doc due to inherent or acquired drug resistance $(4,5)$.

Doc is considered to function as a microtubule inhibitor by binding to $\beta$-tubulin and preventing microtubule disassembly. Hence, Doc is able to arrest cells in the $\mathrm{G}_{2} / \mathrm{M}$-phase of the cell cycle and induce cell death. A number of studies have suggested that Doc induces phosphorylation of B-cell lymphoma 2 (Bcl-2) and Bcl-xL members, thus inactivating their anti-apoptotic capacities (6). In addition, the mitogen-activated protein kinase pathway is considered to be involved in the development of drug resistance in prostate cancer cells $(7,8)$. Nevertheless, the association between the expression of Bcl-2 family members and Doc resistance remains controversial (9). Overexpression of pro-apoptotic proteins caspase- 9 and Bcl-2 interacting protein 3 in resistant prostate cancer cells was observed in previous studies $(10,11)$. However, few studies have carefully examined the regulation of these mechanisms in response to initial treatment with Doc. Thus, identification of the mechanistic basis of Doc-induced cell death in prostate cancer will improve our understanding on the resistance mechanism.

In the present study, the antiproliferative effect of Doc on androgen-dependent and androgen-independent human prostate cancer cells was investigated. In addition, we also investigated signaling pathways involved in Doc-induced cell apoptosis. 


\section{Materials and methods}

Reagents. MTT was purchased from Sigma-Aldrich (Merck KGaA, Darmstadt, Germany). Dulbecco's modified Eagle's medium (DMEM) and Annexin V-FITC/propidium iodide (PI) were purchased from Beyotime Institute of Biotechnology (Hangzhou, China). Fetal bovine serum (FBS) was obtained from Sijingqing Biotechnology Co., Ltd. (Hangzhou, China). Monoclonal antibodies against total protein kinase B (Akt; 1:1,000; cat. no. ab179463; Abcam, Cambridge, UK), phospho-Akt (1:1,000; cat. no. ab133458; Abcam), Bcl-2 (1:1,000; cat. no. ab59348; Abcam), Bcl-2-associated death promoter (Bad; 1:1,000; cat. no. ab32445; Abcam), caspase-3 (1:1,000; cat. no. ab4051; Abcam), caspase-9 (1:1,000; cat. no. ab52298; Abcam) and $\beta$-actin $(1: 1,000$; cat. no. ab16039; Abcam) were used as primary antibodies. Horseradish peroxidase-conjugated goat anti-rabbit immunoglobulin G (1:1,000; cat. no. 31460; Thermo Fisher Scientific, Inc., Waltham, MA, USA) was used as secondary antibody.

Cell culture. Three human prostate cancer cell lines, namely PC-3 [androgen receptor (AR)-negative], DU-145 (AR-negative) and LNCaP (AR-sensitive) were purchased from The American Type Culture Collection (Manassas, VA, USA) and were maintained in DMEM supplemented with $10 \%$ (v/v) FBS and antibiotics at $37^{\circ} \mathrm{C}$ with $5 \% \mathrm{CO}_{2}$. After 3-4 days of culture, the cells were detached from the surface by trypsinization and reseeded into the appropriate plates for use in further experiments.

MTT assay. Cell proliferation was evaluated by an MTT assay. Briefly, cells were seeded into 96-well plates at a density of $4 \times 10^{3}$ cells per well in $100 \mu 1$ medium and cultured for $\sim 24 \mathrm{~h}$. Next, PC-3, DU-145 and LNCaP cells were treated with Doc at the doses of 0-64, 0-40 and 0-8 nM, respectively. Six replicated samples were assayed for each concentration. Cells were cultured for $48 \mathrm{~h}$, followed by the addition of $20 \mu \mathrm{l}$ MTT in each well. After $4 \mathrm{~h}$, the supernatant were discarded, $200 \mu \mathrm{l}$ dimethyl sulfoxide (DMSO) was added to each well, and the plate was placed on a shaker for $10 \mathrm{~min}$ to completely dissolve DMSO. Absorbance was then measured at wavelengths of 490 and $630 \mathrm{nM}$. The half maximal inhibitory concentration $\left(\mathrm{IC}_{50}\right)$ was calculated using Origin software, version 8.5 (OriginLab Corporation, Northampton, MA, USA).

Cell apoptosis assay. Cells in the logarithmic growth phase were seeded in 6 -well plates at a density of $2 \times 10^{5}$ cells per well. The three cell lines were divided into three groups each and then incubated with two different concentrations of Doc (4 and $10 \mathrm{nM}$ ) as the positive controls and in the absence of Doc as the negative control. After $48 \mathrm{~h}$, cells were harvested, washed in cold phosphate-buffered saline (PBS), and then treated with Annexin V-FITC and PI using an Apoptosis Detection kit with PI, according to the manufacturer's protocol. Annexin V-FITC and PI binding was detected with an Attune flow cytometer (Thermo Fisher Scientific, Inc.), and flow cytometric analysis was performed using BD CellQuest software (BD Biosciences, Franklin Lakes, NJ, USA).

Cell cycle analysis. The DNA content during the cell cycle phases was evaluated by flow cytometry. Briefly, $4 \times 10^{5}$ PC-3,
DU-145 and LNCaP cells were seeded and were treated with Doc at concentrations of 4, 10 and $2 \mathrm{nM}$, respectively. Cells were then incubated for $48 \mathrm{~h}$, and cell pellets were washed and fixed in cold $70 \%$ ethanol at $4^{\circ} \mathrm{C}$ overnight. On the following day, the cell pellets were washed three times and resuspended in PBS, followed by treatment with RNase $(50 \mu \mathrm{g} / \mathrm{ml})$ for $1 \mathrm{~h}$. Next, $5 \mu \mathrm{l}$ PI $(1 \mathrm{mg} / \mathrm{ml})$ was added to a final concentration of $50 \mu \mathrm{g} / \mathrm{ml}$ and incubated for $1 \mathrm{~h}$ at room temperature in the dark. Subsequent to staining of DNA by PI, samples were evaluated using the Attune flow cytometer, and analysis was performed using the BD CellQuest software.

Protein extraction and western blotting. Following treatment for 24 or $48 \mathrm{~h}$, total protein was extracted using a cell lysis buffer (Thermo Fisher Scientific, Inc.). Protein concentration in the supernatant was determined using a Bio-Rad protein assay kit (Bio-Rad Laboratories, Inc., Hercules, CA, USA). Next, protein $(20 \mu \mathrm{g})$ was subjected to $12 \%$ SDS-PAGE and transferred to a polyvinylidene difluoride membrane. Subsequent to blocking in non-fat dry milk for $2 \mathrm{~h}$ at room temperature, the membrane was incubated overnight at $4^{\circ} \mathrm{C}$ with total $\mathrm{Akt}$, phospho-Akt, Bcl-2, Bad, caspase-3 and caspase-9 primary antibodies. The membrane was then washed three times with Tris-buffered saline (10 min each time), followed by incubation with secondary antibody for $2 \mathrm{~h}$ at room temperature. Signal development was performed using an enhanced chemiluminescence kit. Signals were captured and band densities were quantified using Bandscan software, version 5.0 (ProZyme; Agilent Technologies, Inc., Santa Clara, CA, USA).

Statistical analysis. Data are presented as the mean \pm standard deviation. Analysis of variance with Tukey-Kramer test adjustment was used for comparisons among multiple groups, while Student' test was used to examine comparisons between two groups. All analyses were performed using SPSS software, version 11.0 (SPSS, Inc., Chicago, IL, USA). Probability values of $\mathrm{P}<0.05$ were considered to denote statistically significant differences.

\section{Results}

Effects of Doc on the growth of human prostate cancer cells. Following treatment for $48 \mathrm{~h}$, the inhibitory effects of Doc on the three prostate cancer cell lines PC-3, DU-145 and LNCaP were explored by an MTT assay. The results presented in Fig. 1 demonstrate that, upon treatment with Doc, cell viability in the three cell lines decreased in a concentration-dependent manner. The $\mathrm{IC}_{50}$ values of the effect of Doc on PC-3, DU-145 and LNCaP cells were 3.72, 4.46 and $1.13 \mathrm{nM}$, respectively. Among the three cell lines, $\mathrm{LNCaP}$ is an androgen-dependent prostate cancer cell line, while the other two cell lines are androgen-independent (12). The study results indicated that PC-3 and DU-145 cells were more resistant to Doc treatment, as their $\mathrm{IC}_{50}$ values were approximately threefold and fourfold higher in comparison with that of LNCaP cells, respectively.

Effects of Doc on the apoptosis of human prostate cancer cells. To examine the mechanism underlying the antitumor effect of Doc, flow cytometric analysis with Annexin V/PI staining was 

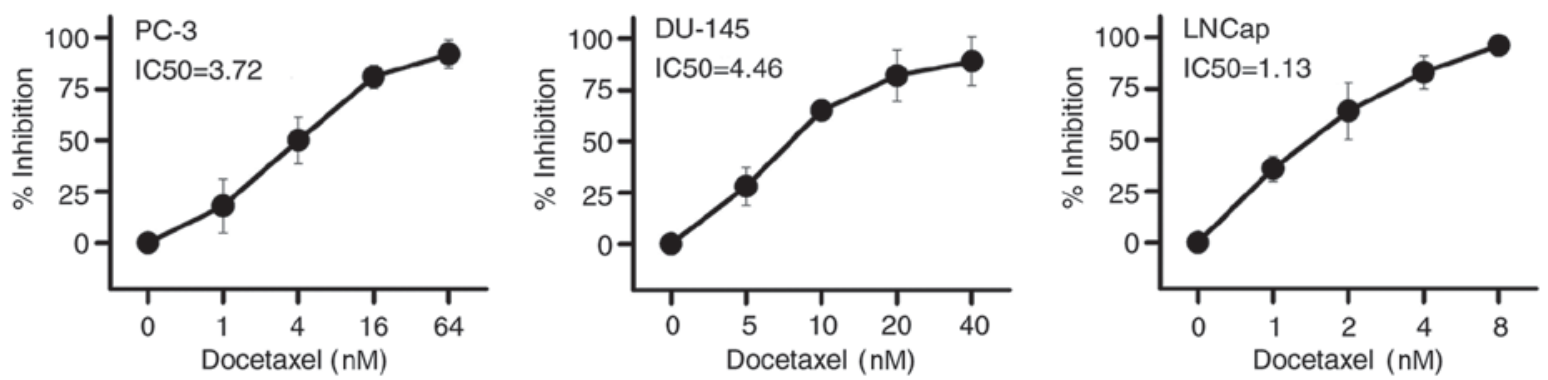

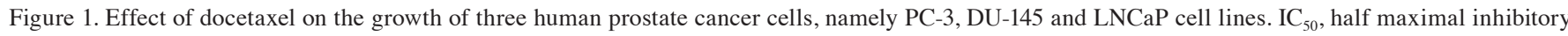
concentration.
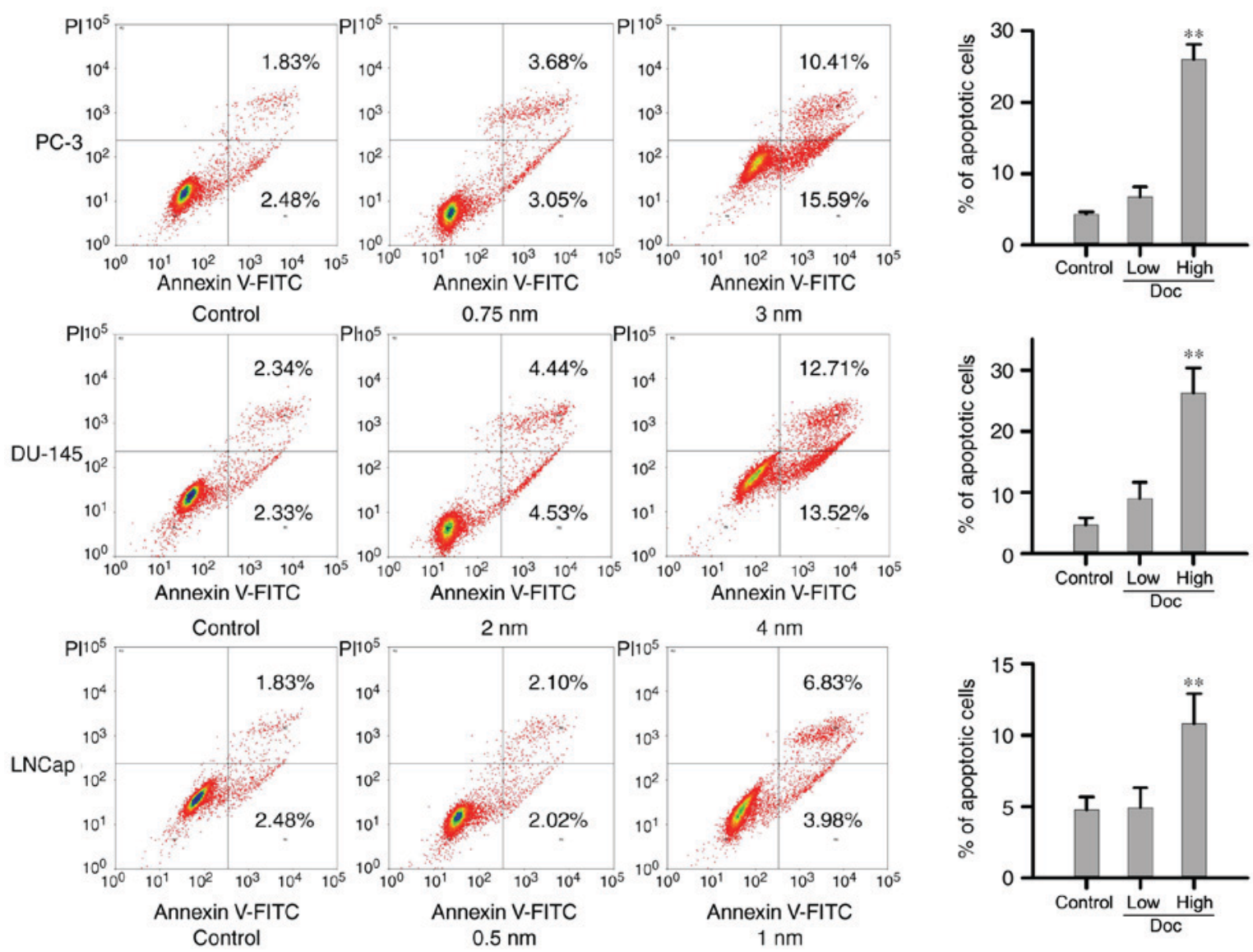

Figure 2. Effects of Doc on the apoptosis of human prostate cancer cells. Cells were treated with a low or high concentration of Doc, and flow cytometric assay was performed. ${ }^{* *} \mathrm{P}<0.01$, vs. control and low Doc groups. Doc, docetaxel.

performed. Cells were exposed to low and high concentrations of Doc, which were determined according to the $\mathrm{IC}_{50}$ value of each cell line. The low Doc dose for PC-3, DU-145 and LNCaP cells was $0.75,2$ and $0.5 \mathrm{nM}$, respectively, while the high dose was 3, 4 and $1 \mathrm{nM}$, respectively. As presented in Fig. 2, low concentrations of Doc had no effect on cell death in all cells lines. Compared with the negative control and with the cells treated with a low concentration of Doc, treatment with high dose of Doc significantly increased the proportion of Annexin $\mathrm{V}^{+}$apoptotic cells.

Effect of Doc on cell cycle phase distribution. Cultured human prostate cancer PC-3, DU-145 and LNCaP cells were exposed to Doc at the concentrations of 4,10 and $2 \mathrm{nM}$, respectively.
As presented in Fig. 3, it was observed that treatment with Doc led to marked cell cycle arrest at $\mathrm{G}_{2} / \mathrm{M}$ phase, as observed by the significant increase in the percentage of cells at this phase in PC-3 and DU145 cells, as compared with the untreated cells.

Effects of Doc on the protein levels of Bcl-2, Bad, phospho-Akt and caspase-3/9. The study next explored the expression of proteins associated with the development of Doc resistance in prostate cancer cells. Western blot assay was used to assess the expression of Bcl-2, total Akt, phospho-Akt, Bcl-2, Bad, caspase- 3 and caspase- 9 at the protein levels after 24 and $48 \mathrm{~h}$ of Doc treatment. As shown in Fig. 4, compared with the control group, treatment with Doc for $24 \mathrm{~h}$ led to significantly decreased expression of anti-apoptotic Bcl-2 protein. The 


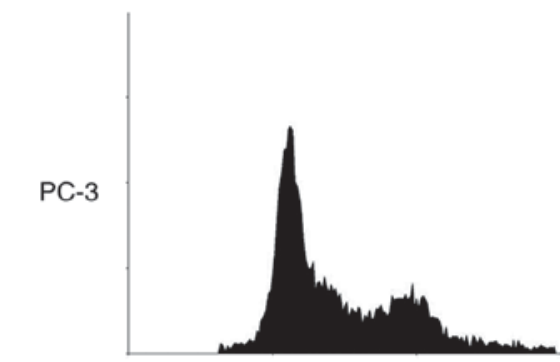

Docetaxel-

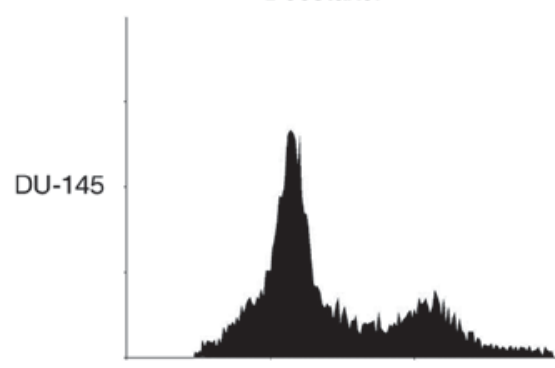

Docetaxel-

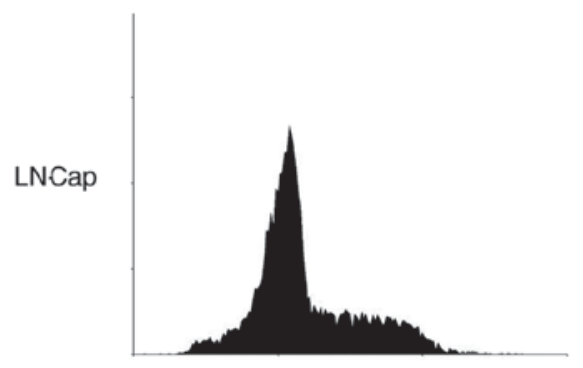

Docetaxel-

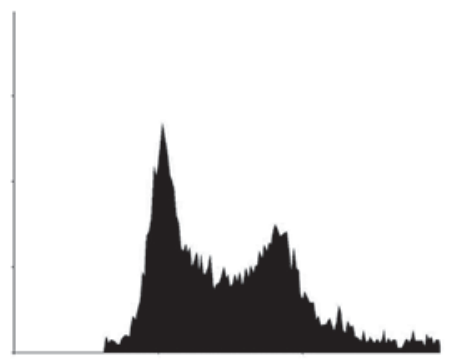

Docetaxel+

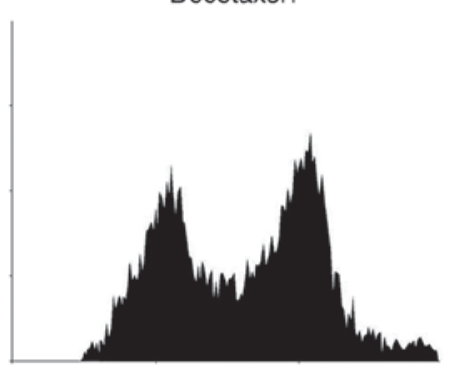

Docetaxel+

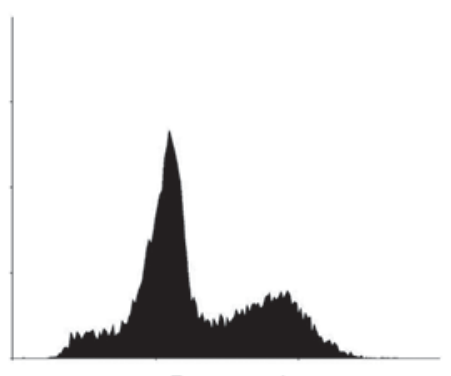

Docetaxel+
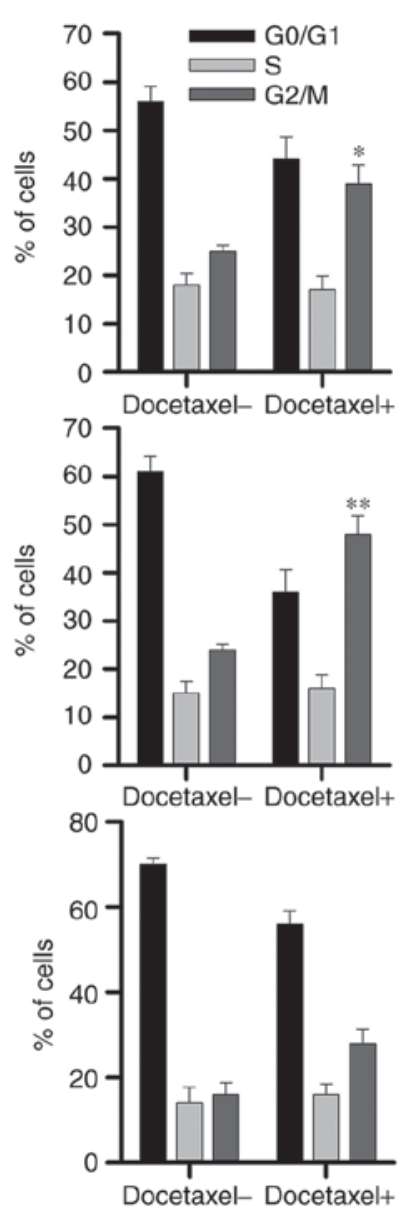

Figure 3. Effects of docetaxel on the cell cycle phase distribution of PC-3, DU-145 and LNCaP cells, examined by flow cytometry. ${ }^{*} \mathrm{P}<0.05$ and ${ }^{* *} \mathrm{P}<0.01$, vs. corresponding phase in the group without docetaxel treatment.
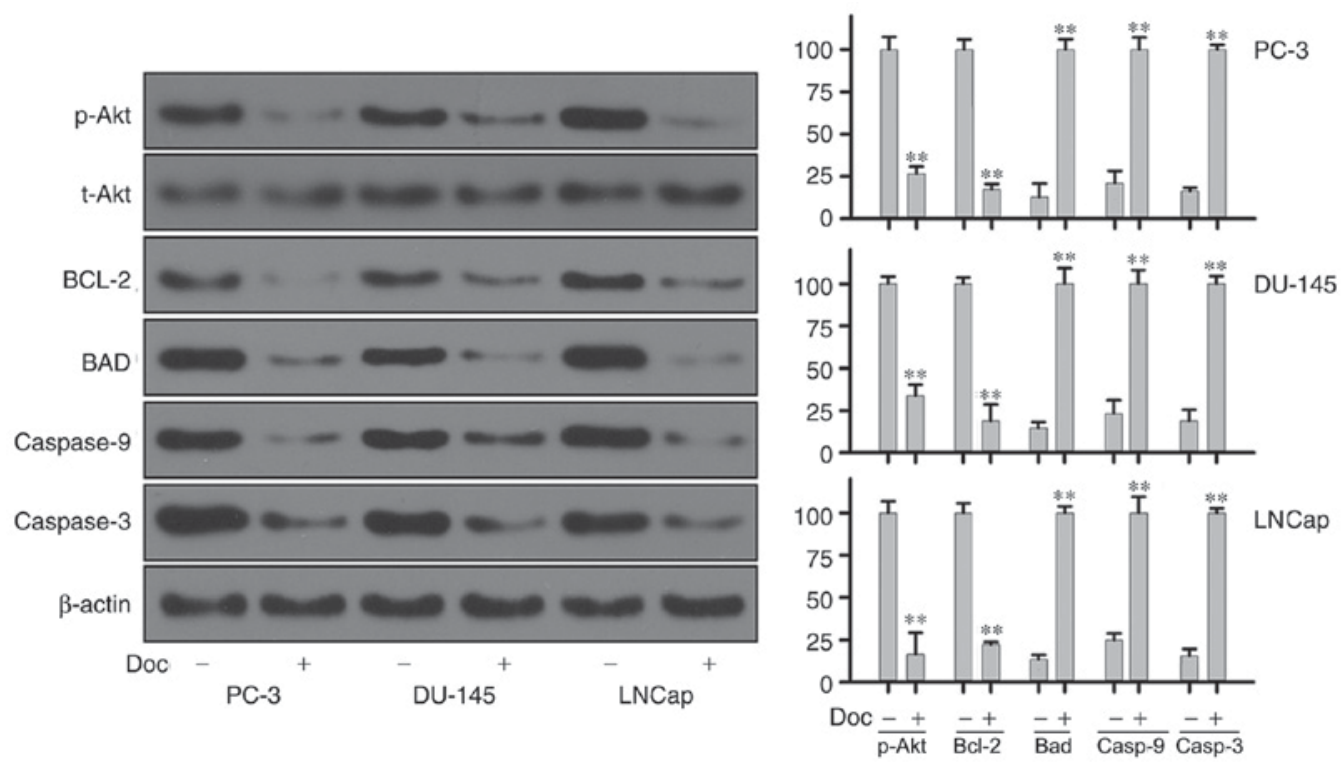

Figure 4. Effects of Doc treatment for $24 \mathrm{~h}$ on the protein expression levels of Bcl-2, Bad, total Akt, phospho-Akt and caspase-3/9. Western blot analysis of protein levels and quantified results are shown. ${ }^{* *} \mathrm{P}<0.01$ vs. group without Doc treatment. Doc, docetaxel; Bcl-2, B-cell lymphoma 2; Bad, Bcl-2-associated death promoter; Akt, protein kinase B.

activity of p-Akt was decreased significantly, while total Akt level remained stable. Treatment of PC-3, DU-145 and LNCaP cell lines with Doc also resulted in significant increase in the levels of caspase-3, caspase- 9 and pro-apoptotic protein Bad. Protein expression was further examined at $48 \mathrm{~h}$, and similar results were obtained (Fig. 5). 

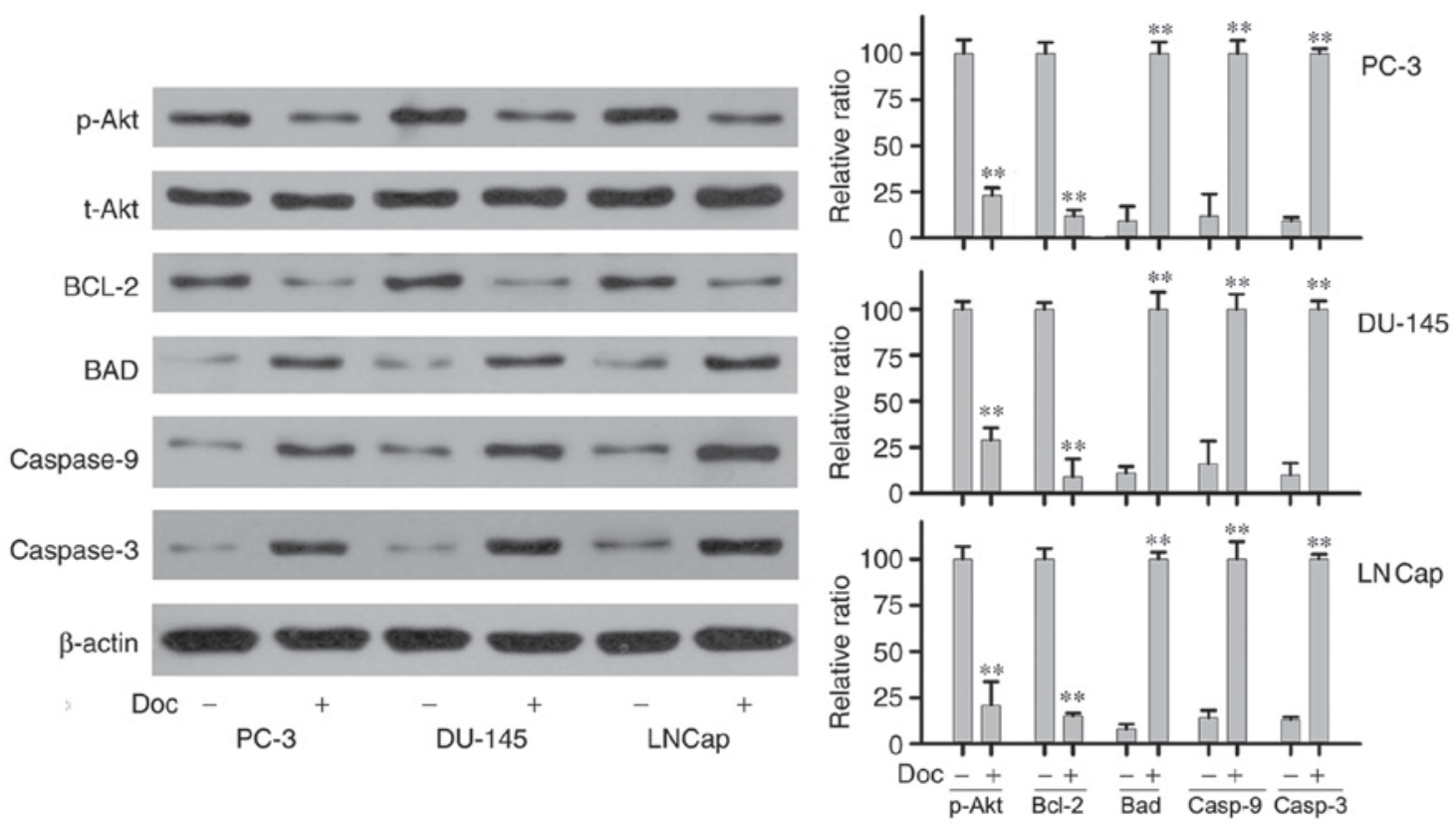

Figure 5. Effects of Doc treatment for $48 \mathrm{~h}$ on the protein expression levels of Bcl-2, Bad, total Akt, phospho-Akt and caspase-3/9. Western blot analysis of protein levels and quantified results are displayed. ${ }^{* *} \mathrm{P}<0.01$ vs. group without Doc treatment. Doc, docetaxel; Bcl-2, B-cell lymphoma 2; Bad, Bcl-2-associated death promoter; Akt, protein kinase B.

\section{Discussion}

In spite of the significantly improved survival, prostate cancer remains a clinical challenge due to the fact that, in a certain portion of patients, prostate cancer may progress to metastatic castration-resistant prostate cancer with no curative treatment options $(2,3)$. Doc is an effective cytotoxic agent that provides survival benefits for patients with castration-resistant tumors (13). However, clinical resistance to Doc remains a challenge in clinical practice. Growing evidence has demonstrated the complexity of the mechanism underlying Doc resistance, which includes cellular anti-apoptotic, AR-mediated redox signaling pathways (14-16). In the current study, the inhibitory and apoptotic effects of Doc on androgen-dependent or androgen-independent prostate cancer cells were initially examined. The study then attempted to explore the regulation of Bcl-2 and phosphoinositide 3-kinase (PI3K)/Akt signaling pathway in Doc-induced apoptosis.

The results reported in the present study confirmed that Doc exerted an inhibitory effect on the growth of cultured prostate cancer cells in a dose-independent manner. The $\mathrm{IC}_{50}$ values for the effect of Doc in PC-3, DU-145 and LNCaP cells were $3.72,4.46$ and $1.13 \mathrm{nM}$, respectively. These results indicated that Doc had a stronger inhibitory effect on the AR-dependent LNCaP cells, as compared with that on AR-independent prostate cancer cells PC-3 and DU-145. In respect to Doc-induced apoptosis, the current data are in agreement with previous findings indicating that a low dose of Doc causes no apoptotic cell death, which is accompanied by senescence necrosis and mitotic catastrophe (17-19). AR signaling is known to serve a crucial role in the progression of prostate cancer. Dysregulation of AR signaling and transcriptional activity stimulates resistance to Doc (20). Aberrant AR pathway activation and various splice variant isoforms are frequently observed in advanced prostate cancer (21). At present, the molecular mechanism of the differences in Doc sensitivity is unknown. In a small scale clinical trial, Doc was proven to exert a therapeutic effect on early hormone-sensitive prostate cancer, without affecting testosterone levels (22). In future studies, it would be of interest to explore the impact of low-dose Doc treatment on hormone-sensitive prostate cancer compared with the effect of traditional anti-androgen therapy. It would also be interesting to explore the mechanical differences between inherent and therapy-induced AR activation upon initial treatment with Doc.

To examine whether the strong effects of Doc treatment on the three prostate cancer cell lines were mediated through apoptosis-associated signaling pathways, the expression levels of associated genes were assessed at the protein levels in the present study. Previous studies have demonstrated that taxanes inhibit the anti-apoptotic protein Bcl-2 by stabilization of microtubules, leading to apoptosis $(20,23)$. Bcl-2, a proto-oncogene, is one of the most widely studied negative regulators of apoptotic cascades. It is considered that $\mathrm{Bcl}-2$ prevents the release of cytochrome $c$ and consequently blocks the activation of the caspase cascade (24). In the present study, it was observed that treatment of prostate cancer cells lines PC-3, DU-145 and LNCaP with Doc significantly inhibited Bcl-2 activity, and further upregulated the pro-apoptotic Bad, caspase-3 and caspase-9 proteins. Recent studies suggested that activation of Akt directly affects the apoptosis pathway by targeting and downregulating the levels of Bcl-2 family members, including Bad and Bcl-2-associated X protein, resulting in cell survival $(25,26)$. Emerging evidence revealed a negative feedback link between PI3K/Akt and AR $(25,26)$. Furthermore, activation of Akt induced the phosphorylation of AR, resulting in inhibition of the AR-induced apoptotic pathway, whereas AR inhibition was reported to activate the PI3K/Akt signaling pathway $(25,26)$. The results of the present study revealed that treatment of the three prostate cancer cell lines with Doc markedly decreased the level of phospho-Akt. 
A certain decrease, although not significant, was also observed in AR-dependent prostate cancer cells (namely LNCaP), as compared with that detected in AR-independent prostate cancer cells, implying a potential interplay between AR and PI3K/Akt when prostate cancer cells are treated with Doc. Given the central role of PI3K/Akt signaling pathway on the growth, proliferation, motility, survival and angiogenesis of tumor cells $(27,28)$, there is great need for understanding the associations between PI3K/Akt and AR pathway in Doc-induced apoptosis. In addition, other pathways may participate in Doc-induced apoptosis through AR-dependent or AR-independent pathways; however, further studies are required to investigate the involvement of other pathways.

It has been reported that the development of Doc resistance in prostate cancer is associated with AR activation (29), which is consistent with the findings of the present study, further confirming the reliability of our data. Nevertheless, compared with a 2D cell culture system, a 3D cell culture system that exhibits a more similar behavior to in vivo conditions (30) should be performed to further confirm the conclusions of the present study. Doc has been widely used in the clinical treatment of prostate cancer (31), and multiple pathways have been proven to be involved in the Doc-mediated therapeutic response in this disease, such as p53/p21WAF1/CIP1, p27KIP1 and Notch pathways $(32,33)$. However, the involvement of Akt signaling in this process is rarely studied. Thus, the present study systemically investigated the role of Akt signaling in Doc-mediated therapeutic responses in prostate cancer. A number of pathways, such as type I insulin-like growth factor (34), have been proven to be involved in androgen-dependent and androgen-independent prostate cancer, and our future studies will focus on these pathways.

In conclusion, the present study demonstrated that Doc strongly inhibited the growth and induced the apoptosis of human prostate cancer cells. AR-dependent prostate cancer cells were more sensitive to Doc in comparison with androgen-independent cells. The effects of Doc on growth inhibition and apoptosis in prostate cancer cells were associated with inhibition of PI3K/Akt activation, decreased levels of Bcl-2 and increased caspase-3/9 activation.

\section{Acknowledgements}

Not applicable.

\section{Funding}

The present study was funded by The Agricultural and Social Class Science and Technology Plan Project of Ninghai County (grant no. 2013B11).

\section{Availability of data and materials}

The datasets used and/or analyzed during the current study are available from the corresponding author on reasonable request.

\section{Authors' contributions}

JJ and CY designed and conceived the study. CY and WZ performed experiments and collected the data. JW and PC analyzed and interpreted the data. JJ wrote the manuscript. All authors read and approved the final manuscript.

\section{Ethics approval and consent to participate}

Not applicable.

\section{Patient consent for publication}

Not applicable.

\section{Competing interests}

The authors declare that they have no competing interests.

\section{References}

1. Ferlay J, Soerjomataram I, Dikshit R, Eser S, Mathers C, Rebelo M, Parkin DM, Forman D and Bray F: Cancer incidence and mortality worldwide: Sources, methods and major patterns in GLOBOCAN 2012. Int J Cancer 136: E359-E386, 2015.

2. Eyre H, Kahn R and Robertson RM; ACS/ADA/AHA Collaborative Writing Committee: Preventing cancer, cardiovascular disease, and diabetes: A common agenda for the American cancer society, the American diabetes association, and the American heart association. CA Cancer J Clin 54: 190-207, 2004.

3. Brunelli A, Kim AW, Berger KI and Addrizzo-Harris DJ: Physiologic evaluation of the patient with lung cancer being considered for resectional surgery: Diagnosis and management of lung cancer, 3rd ed: American College of Chest Physicians evidence-based clinical practice guidelines. Chest 143 (Suppl 5): e166S-e190S, 2013.

4. Lee JL, Kim JE, Ahn JH, Lee DH, Lee J, Kim CS, Hong JH, Hong B, Song C and Ahn H: Efficacy and safety of docetaxel plus prednisolone chemotherapy for metastatic hormone-refractory prostate adenocarcinoma: Single institutional study in Korea. Cancer Res Treat 42: 12-17, 2010.

5. Petrylak DP, Tangen CM, Hussain MH, Lara PN Jr, Jones JA, Taplin ME, Burch PA, Berry D, Moinpour C, Kohli M, et al: Docetaxel and estramustine compared with mitoxantrone and prednisone for advanced refractory prostate cancer. N Engl J Med 351: 1513-1520, 2004.

6. Montero A, Fossella F, Hortobagyi G and Valero V: Docetaxel for treatment of solid tumours: A systematic review of clinical data. Lancet Oncol 6: 229-239, 2005.

7. West KA, Castillo SS and Dennis PA: Activation of the PI3K/Akt pathway and chemotherapeutic resistance. Drug Resist Updat 5: 234-248, 2002.

8. Pritchard AL and Hayward NK: Molecular pathways: Mitogen-activated protein kinase pathway mutations and drug resistance. Clin Cancer Res 19: 2301-2309, 2013.

9. Mohammadian J, Sabzichi M, Molavi O, Shanehbandi D and Samadi N: Combined treatment with stattic and docetaxel alters the $\mathrm{Bax} / \mathrm{Bcl}-2$ gene expression ratio in human prostate cancer cells. Asian Pac J Cancer Prev 17: 5031-5035, 2016.

10. Yoo NJ, Kim MS and Park SW: Expression analysis of caspase-6, caspase-9 and BNIP3 in prostate cancer. Tumori 96: 138-142, 2010.

11. Winter RN, Kramer A, Borkowski A and Kyprianou N: Loss of caspase- 1 and caspase-3 protein expression in human prostate cancer. Cancer Res 61: 1227-1232, 2001.

12. Webber MM, Bello D and Quader S: Immortalized and tumorigenic adult human prostatic epithelial cell lines: Characteristics and applications Part 2. Tumorigenic cell lines. Prostate 30: 58-64, 1997.

13. Basch EM, Somerfield MR, Beer TM, Carducci MA, Higano CS, Hussain MH and Scher HI; American Society of Clinical Oncology: American Society of Clinical Oncology endorsement of the cancer care ontario practice guideline on nonhormonal therapy for men with metastatic hormone-refractory (castration-resistant) prostate cancer. J Clin Oncol 25: 5313-5318, 2007.

14. Hughes C, Murphy A, Martin C, Sheils O and O'Leary J: Molecular pathology of prostate cancer. J Clin Pathol 58: 673-684, 2005. 
15. Muenchen HJ, Poncza PJ and Pienta KJ: Different docetaxel-induced apoptotic pathways are present in prostate cancer cell lines LNCaP and PC-3. Urology 57: 366-370, 2001.

16. Hwang C: Overcoming docetaxel resistance in prostate cancer: A perspective review. Ther Adv Med Oncol 4: 329-340, 2012.

17. Morse DL, Gray H, Payne CM and Gillies RJ: Docetaxel induces cell death through mitotic catastrophe in human breast cancer cells. Mol Cancer Ther 4: 1495-1504, 2005.

18. Fabbri F, Amadori D, Carloni S, Brigliadori G, Tesei A, Ulivi P, Rosetti M, Vannini I, Arienti C, Zoli W and Silvestrini R: Mitotic catastrophe and apoptosis induced by docetaxel in hormone-refractory prostate cancer cells. J Cell Physiol 217: 494-501, 2008

19. Fabbri F, Carloni S, Brigliadori G, Zoli W, Lapalombella R and Marini M: Sequential events of apoptosis involving docetaxel a microtubule-interfering agent: A cytometric study. BMC Cell Biol 7: 6, 2006.

20. Kahn B, Collazo J and Kyprianou N: Androgen receptor as a driver of therapeutic resistance in advanced prostate cancer. Int J Biol Sci 10: 588-595, 2014.

21. Attar RM, Takimoto CH and Gottardis MM: Castration-resistant prostate cancer: Locking up the molecular escape routes. Clin Cancer Res 15: 3251-3255, 2009.

22. Gravis G,Fizazi K, Joly F, Oudard S, Priou F,Esterni B,Latorzeff I, Delva R, Krakowski I, Laguerre B, et al: Androgen-deprivation therapy alone or with docetaxel in non-castrate metastatic prostate cancer (GETUG-AFU 15): A randomised, open-label, phase 3 trial. Lancet Oncol 14: 149-158, 2013.

23. Loriot Y and Fizazi K: Taxanes: Still a major weapon in the armamentarium against prostate cancer. Eur Urol 63: 983-985, 2013.

24. Akinleye A, Avvaru P, Furqan M, Song Y and Liu D: Phosphatidylinositol 3-kinase (PI3K) inhibitors as cancer therapeutics. J Hematol Oncol 6: 88, 2013.

25. Morgan TM, Koreckij TD and Corey E: Targeted therapy for advanced prostate cancer: Inhibition of the PI3K/Akt/mTOR pathway. Curr Cancer Drug Targets 9: 237-249, 2009.

26. Lin HK, Yeh S, Kang HY and Chang C: Akt suppresses androgen-induced apoptosis by phosphorylating and inhibiting androgen receptor. Proc Natl Acad Sci USA 98: 7200-7205, 2001.
27. Thomas C, Lamoureux F, Crafter C, Davies BR, Beraldi E, Fazli L, Kim S, Thaper D, Gleave ME and Zoubeidi A: Synergistic targeting of PI3K/AKT pathway and androgen receptor axis significantly delays castration-resistant prostate cancer progression in vivo. Mol Cancer Ther 12: 2342-2355, 2013.

28. Osaki M, Oshimura M and Ito H: PI3K-Akt pathway: Its functions and alterations in human cancer. Apoptosis 9: 667-676, 2004.

29. Komura K, Jeong SH, Hinohara K, Qu F, Wang X, Hiraki M, Azuma H, Lee GS, Kantoff PW and Sweeney CJ: Resistance to docetaxel in prostate cancer is associated with androgen receptor activation and loss of KDM5D expression. Proc Natl Acad Sci USA 113: 6259-6264, 2016.

30. Souza AG, Silva IBB, Campos-Fernandez E, Barcelos LS, Souza JB, Marangoni K, Goulart LR and Alonso-Goulart V: Comparative assay of $2 \mathrm{D}$ and $3 \mathrm{D}$ cell culture models: Proliferation, gene expression and anticancer drug response. Curr Pharm Des 24: 1689-1694, 2018.

31. James ND and Mason M: Docetaxel and/or zoledronic acid for hormone-naïve prostate cancer: First survival results from STAMPEDE. J Clin Oncol 33: 5001, 2015.

32. Singh SK, Banerjee S, Acosta EP, Lillard JW and Singh R: Resveratrol induces cell cycle arrest and apoptosis with docetaxel in prostate cancer cells via a p53/p21WAF1/CIP1 and p27KIP1 pathway. Oncotarget 8: 17216-17228, 2017.

33. Cui D, Dai J, Keller JM, Mizokami A, Xia S and Keller ET: Notch pathway inhibition using PF-03084014, a $\gamma$-secretase inhibitor (GSI), enhances the antitumor effect of docetaxel in prostate cancer. Clin Cancer Res 21: 4619-4629, 2015.

34. Wu JD, Odman A, Higgins LM, Haugk K, Vessella R, Ludwig DL and Plymate SR: In vivo effects of the human type I insulin-like growth factor receptor antibody A12 on androgen-dependent and androgen-independent xenograft human prostate tumors. Clin Cancer Res 11: 3065-3074, 2005. 